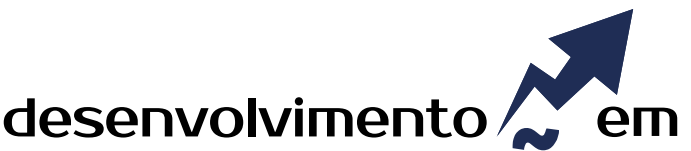 QUESTÃO
}

\section{Política Pública de Turismo e Desenvolvimento Local: Análise sob o Enfoque da Escala Humana}

http://dx.doi.org/10.21527/2237-6453.2020.52.142-158

Recebido em: 25/9/2017

Aceito em: 3/3/2020

\author{
Aychá Freitas Santos ${ }^{1}$ João Pedro de Castro Nunes Pereira ${ }^{2}$
}

\begin{abstract}
RESUMO
Desde o final do século 19 várias abordagens sobre o tema do desenvolvimento foram discutidas na literatura acadêmica, em especial a abordagem do desenvolvimento vinculada à concepção econômica. A partir da década de 80, entretanto, outras abordagens foram ganhando espaço no ambiente acadêmico, que passa a dar oportunidade para abordagens com enfoque social, envolvendo temáticas abrangendo as políticas públicas direcionadas à educação, saúde, moradia, saneamento, lazer, etc. Neste novo cenário de desenvolvimento, com características sociais, é que surgem autores buscando analisar a satisfação das necessidades humanas básicas. Para fins de estudo, utilizou-se a abordagem sobre Escala Humana de Max-Neef (1994) como fator central do estudo sobre as políticas públicas vinculadas ao setor turístico no Estado da Bahia. Diante do exposto, a pesquisa tem como objetivo geral propor uma estrutura analítica para avaliação das políticas públicas do turismo, na condição de agente de promoção do desenvolvimento local, sob a ótica da Escala Humana. Para tanto, optou-se pelo recorte da análise dos resultados do Proetur, considerada uma das principais ações associadas à Política Nacional de Turismo. A opção metodológica valeu-se da avaliação de indicadores sociais e econômicos ligados ao conceito da escala humana. Os resultados encontrados apontam para a pertinência da estrutura proposta que, sob esta ótica, indica uma necessidade premente de que as Políticas Públicas de Turismo priorizem sua atenção as zonas turísticas mais afastadas do litoral baiano.
\end{abstract}

Palavras-chave: Escala humana. Políticas públicas. Turismo. Estado da Bahia. Desenvolvimento local.

\section{PUBLIC POLICY OF TOURISM AND LOCAL DEVELOPMENT: ANALYSIS UNDER THE HUMAN SCALE APPROACH}

\section{ABSTRACT}

Since the end of the 19th century, several approaches on the topic of development have been discussed in the academic literature, the approach to development associated with economic strategies. However, since the 1980s, other approaches have been gaining academic space, which has shifted to space for approaches with a social focus, involving themes covering political policies directed towards education, health, sanitation, leisure, etc. development scenario, with social characteristics, that search authors seek to analyze the satisfaction of basic human needs. For study purposes, use the Max-Neef Human Scale approach (1994) as a central factor in the study of public policies related to the tourism sector in the State of Bahia. Given the above, a research has the general objective of proposing an analytical structure for the evaluation of public tourism policies, as an agent for promoting local development, from the perspective of the Human Scale. To do so, choose the Proetur results analysis feature, considered one of the main actions related to the National Tourism Policy. A methodological option for evaluating social and economic indicators associated with the concept of human scale. The results found point to the pertinence of the proposed structure from this perspective, pointing out a necessary need for public tourism policies, prioritizing its attention as tourist areas furthest from the Bahian coast.

Keywords: Human Scale. Public Policies. Tourism. State of Bahia. Local Development.

\footnotetext{
${ }^{1}$ Mestre em Economia Regional e Políticas Públicas pela Universidade Estadual de Santa Cruz (Uesc). http://lattes.cnpq.br/3444911432321582. https://orcid.org/0000-0002-6267-5156. aychafreitas@gmail.com

2 Doutor em Engenharia de Produção pela Universidade de São Paulo (USP). Professor da Universidade Estadual de Santa Cruz (Uesc). http:// lattes.cnpq.br/9289298095076064. https://orcid.org/0000-0001-5989-7359. jpcnpereira@gmail.com
} 
Em que pese a importância de se estudar o desenvolvimento a partir da sua complexidade, é possível encontrar na literatura acadêmica diversos estudos trazendo distintas abordagens e concepções sobre o tema, em função do propósito de cada um desses estudos.

Historicamente o fenômeno do desenvolvimento era fundamentalmente vinculado à concepção econômica e com isso era tratado como sinônimo de crescimento. Ao longo dos anos, sobretudo a partir de 1980, o desenvolvimento começou a ser analisado como um processo de transformação social (ALVES, 2008) em que o sucesso para a promoção do desenvolvimento local passa a ser encarado como resultado da articulação dos agentes (sociais, políticos, econômicos, culturais, públicos ou privados) que propiciem a equidade, qualidade de vida e bem-estar social (ZAPATA et al., 2004).

Nesse contexto, destaca-se o trabalho de Max-Neef (1994), que sugere uma abordagem do desenvolvimento sob o viés social, tendo o indivíduo como foco principal de ação, propondo que o desenvolvimento seja encarado sob uma escala humanista. 0 enfoque de desenvolvimento proposto por este autor permite a expansão das abordagens sobre o tema, na medida em que sob essa perspectiva os fatores econômicos são parte do processo de desenvolvimento e não seu todo. Nessa mesma linha analítica, integra-se a este pensamento do desenvolvimento à escala humana as ideias de Furtado (2000), que afirma ser o desenvolvimento não apenas um papel exclusivamente econômico, mas também a satisfação das necessidades humanas.

Associado a este cenário, no Brasil, o turismo começou a ter destaque no cenário econômico como forte dinamizador do desenvolvimento local, por possuir uma interdependência estrutural com diversos setores, principalmente com relação às indústrias de transformação, comércio, serviços públicos, etc., o qual torna-se importante para amenizar as desigualdades socioeconômicas por meio da geração de emprego e renda (SILVA, 2004). Como uma das formas de valorização dessa atividade econômica, no contexto de uma política pública específica, o Programa de Desenvolvimento do Turismo Prodetur - vinculado à Política Nacional do Turismo, mostrou-se uma opção para a busca de melhores condições para a promoção do desenvolvimento local. Nesse contexto, o Prodetur/NE teve como diretriz criar polos turísticos com investimentos públicos em infraestrutura básica (saneamento, sistema viário e aeroviário, recuperação do patrimônio histórico, etc.). A proposta deste Programa no Nordeste foi basicamente qualificar esta região para o turismo receptivo, intervindo em áreas de interesse turístico (SOUZA; MORAIS, 2011).

Nesse contexto, entende-se que a estratégia do Prodetur como ferramenta operacional de uma política pública específica tem como base o modelo exógeno de desenvolvimento, valendo-se de estímulos e externos para iniciar um processo de desenvolvimento interno.

Considerando-se a importância teórica do enfoque da escala humana do desenvolvimento, e a necessidade em verificar o processo da eficácia de políticas públicas do turismo, o presente estudo busca propor uma estrutura analítica para avaliação das políticas públicas do turismo, na condição de agente de promoção do desenvolvimento local, sob a ótica da Escala Humana. 
Dessa forma, o estudo aqui proposto tem como ponto de partida a seguinte questão: Como as políticas públicas de turismo, em especial o Prodetur, podem contribuir para a promoção do desenvolvimento local segundo a ótica da Escala Humana? Nesse sentido, o pressuposto adotado neste estudo é de que as políticas públicas destinadas ao turismo podem promover o desenvolvimento local quando os cidadãos puderem satisfazer suas necessidades sociais e econômicas.

Para tanto, este estudo traz como centro focal de suas atividades o Estado da Bahia, considerando a importância do turismo no cenário econômico baiano associado às vantagens comparativas que o Estado apresenta.

Dessa forma, este artigo está organizado em seis seções. Nesta primeira tem-se a introdução. Na segunda seção é feita uma revisão da literatura que dá sustentação teórica e empírica a este estudo: turismo, políticas públicas e o modelo da escala humana para o desenvolvimento. Na terceira seção são descritos os procedimentos metodológicos utilizados na pesquisa, bem como as limitações relacionadas ao objeto do presente estudo. Na quarta seção apresenta-se uma proposição da estrutura teórico-conceitual para análise do desenvolvimento sob o enfoque da Escala Humana. Já na quinta seção apresenta-se os resultados e as discussões da pesquisa. Por fim, registram-se as considerações finais.

\section{REVISÃO DE LITERATURA}

\section{Turismo}

Os estudos referentes ao objeto do turismo trazem distintas dimensões de análise, que por sua vez podem implicar distintas conceituações, em função das dimensões consideradas (LUCCHIARI, 1998). Aproximando-se do contexto humanístico do desenvolvimento, Urry (2000) destaca que o turismo é para as pessoas.

Para Mcintosh, Goeldner e Ritchie (2003) os impactos positivos do turismo estão relacionados com o efeito multiplicador, pois pode contribuir para o desenvolvimento local além de fornecer uma qualidade de vida melhor para os cidadãos. Já Cruz (2000) analisa os impactos negativos do turismo, ou seja, especulação imobiliária, empregos temporários, falta de capacitação dos moradores locais, etc. A atividade turística "do ponto de vista social, trata-se de um modelo de turismo segregador e excludente" (RODRIGUES, 2006, p. 308).

Krippendorf (2003) propõe uma abordagem também humanizada do turismo, afirmando que "não precisamos de viagens diferentes, mas de pessoas diferentes. Somente uma outra sociedade e outras condições de vida produzirão um outro turista. Uma sociedade doente não pode produzir um turista sadio" (p. 134), ou seja, a agregação de valor ao serviço do turismo depende da condição do local em entender os requisitos dos clientes, que por sua vez devem se mostrar absolutos e conscientes na exposição e construção do turismo a que se propõem. A percepção de "turistas sadios" mostra-se como um reflexo direto de uma sociedade capaz de subsidiar as condições para que este turista construa sua consciência do desejo almejado no processo e que por isso possa usufruir plenamente do momento ofertado, criando condições plenas para satisfação diante do serviço turístico consumido. Constrói-se, portanto, uma con- 
cepção pela qual o turismo passa a assumir importante papel na promoção do desenvolvimento local, inserido num amplo contexto social, cultural e econômico, atuando como um importante "componente de um conjunto mais amplo de iniciativas visando o desenvolvimento" (BRASIL, 2003, p. 145).

Nesse contexto, Cruz (2006) afirma que o turismo para ser um instrumento do desenvolvimento local e regional necessita apresentar: i) um posicionamento mais ativo dos cidadãos, e para isso a capacitação profissional torna-se fator determinante; ii) um bom entendimento de que o turismo é uma das atividades que pode gerar o desenvolvimento, mas é necessário pensar na saúde, educação, política, ou seja, deve-se relacionar o turismo com todas as questões sociais; iii) um olhar detalhado para o território, compreendendo os interesses dos turistas, comerciantes, governos, população local, etc.

Quando o foco é analisar o turismo como uma contribuição para uma sociedade mais sustentável, na qual exista qualidade de vida digna para os moradores locais e uma qualidade de serviços para os turistas tem-se que pensar em um turismo que vise ao desenvolvimento local, em que exista a participação de todos, gerando mudanças socioestruturais, com caráter endógeno (CORIOLANO, 2012).

Assim, a pesquisa aqui proposta visa a trabalhar as políticas públicas de turismo, as quais vêm ao longo dos anos crescendo no cenário econômico brasileiro, tornando-se alvo do governo para promover o desenvolvimento local/regional em áreas consideradas estratégicas em termos econômicos e sociais, por seus propositores.

\section{Políticas públicas para o setor de turismo no Brasil}

A análise da literatura sobre o tema revela que não existe uma definição consolidada sobre política pública, o que proporciona um campo de liberdade para que os pesquisadores no tema possam propor, associar e definir suas concepções de acordo com o foco e objeto de seus estudos. Para Souza (2006), o campo do conhecimento sobre políticas públicas ganhou visibilidade devido a três fatores: i) adoção de políticas restritivas de gasto; ii) substituição das políticas keynesianas do pós-guerra por políticas restritivas de gasto e iii) preocupação dos países em desenvolvimento, principalmente os da América Latina, em fazer coalizões políticas para alavancar o desenvolvimento e a inclusão social (SOUZA, 2006).

De acordo com Queiroz (2012), a expressão "políticas públicas" aplica-se em distintos contextos, podendo assumir as seguintes características: i) atividade governamental, ii) objetivo a ser cumprido, iii) objetivo específico, iv) decisão de governo em uma situação de emergência, v) programas, entre outras características.

Dessa forma, Rua (1998) acredita que as políticas públicas estão relacionadas com a intervenção do Estado na sociedade civil, ou seja, na distribuição de bens públicos para a sociedade. Já para Souza (2006), são instrumentos usados pelo Estado a fim de garantir direitos constitucionais aos cidadãos, principalmente aqueles voltados para a promoção de empregos, educação, saúde, infraestrutura, renda, etc.

De acordo com Queiroz (2012, p. 97) as políticas públicas são os "meios que a administração pública dispõe para a defesa e a concretização dos direitos de liberdade e dos direitos sociais dos cidadãos, estabelecidos numa Constituição Nacional”. 
No ambiente do turismo, Cruz (2001) destaca que o marco das políticas públicas desse setor no Brasil ocorreu no governo de Fernando Henrique Cardoso - FHC (19952003), uma vez que nesse governo dois importantes passos foram dados na construção específica de políticas públicas de turismo: o Programa de Desenvolvimento do Ecoturismo - Proecotur - e o Programa de Desenvolvimento do Turismo - Prodetur/NE - que surgiu a partir da Política Nacional de Turismo, como fator crucial para alavancar a Região Nordeste para o turismo receptivo. O Prodetur/NE foi criado pela Superintendência do Desenvolvimento do Nordeste - Sudene - e pelo Instituto Brasileiro do Turismo atual Embratur (CRUZ, 2001). Trata-se do primeiro programa de ações associado a uma política específica de desenvolvimento local para o turismo.

Com relação às políticas públicas associadas ao turismo no Brasil, trata-se de um movimento político historicamente recente basicamente associado a políticas de governo, representado por ações específicas associadas a planos de governo, sem, contudo, fazer parte das estruturas maiores das políticas de Estado.

No contexto baiano, o marco das políticas públicas do turismo se dá durante o período de 1991-1994, quando se observa um efetivo crescimento do turismo na Bahia, a partir da criação, em 1991, do Programa de Desenvolvimento do Turismo I da Bahia. Vale frisar que as ideias iniciais da construção do Prodetur-I/BA influenciaram mais tarde no desenvolvimento turístico do Nordeste, com base conceitual análoga e mesma denominação do Prodetur/BA, que trouxe para a Bahia mais investimentos/financiamentos e desenvolvimento (FERREIRA; DANTAS, 2013).

O Prodetur foi o primeiro marco setorial do turismo, relacionado ao seu papel como agente promotor do desenvolvimento local. Nas ações governamentais subsequentes observa-se que o desenvolvimento local se apresentava como um resultado indireto de atividades, que em muitos casos, como na questão dos eventos esportivos (Copa do Mundo e Olimpíada) trouxeram um caráter muito mais de alavancamento econômico pontual (durante o desenrolar das atividades) do que pensado e planejado no longo prazo.

Buscando promover a instituição de políticas públicas e ações de desenvolvimento, o Ministério do Turismo, para fins de planejamento, adotou uma classificação de território, considerando aspectos sociais, econômicos e culturais. Assim, no cenário baiano, foram definidas 13 Zonas Turísticas, com base nos marcos territoriais da Política Nacional do Turismo: Baía de Todos os Santos, Caminho do Jiquiriçá, Caminhos do Oeste, Caminhos do Sertão, Caminhos do Sudoeste, Chapada Diamantina, Costa das Baleias, Costa do Cacau, Costa do Dendê, Costa do Descobrimento, Costa dos Coqueiros, Lagos e Cânions do São Francisco e Vale do São Francisco (Figura 1). Esta divisão das Zonas Turísticas do Estado da Bahia iniciou-se no ano de 2013 e teve como critérios adotados as seguintes especificações: possuir oferta turística; apresentar características semelhantes e aspectos que identifiquem os municípios que compõem as regiões; ser limítrofe ou contígua. Com isso, o Estado da Bahia apresenta 13 Zonas Turísticas com 154 municípios que vão do litoral ao sertão e ao cerrado, além de serras e montanhas (BRASIL, 2015). 
Figura 1 - Mapa das 13 Zonas Turísticas do Estado da Bahia

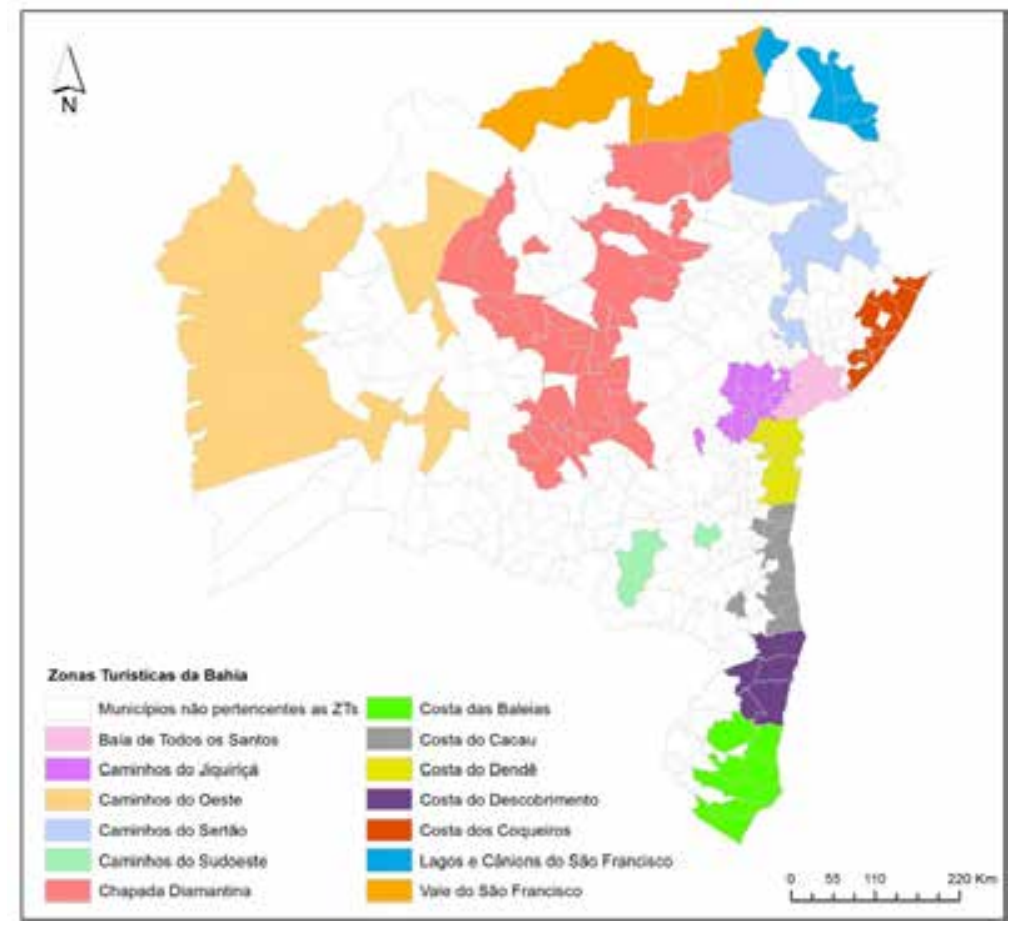

Fonte: Elaboração própria a partir dos dados do Ministério do Turismo.

Dessa forma, o estudo aqui proposto destaca o Prodetur o principal programa para a promoção do desenvolvimento local, pois trabalha com questões relacionadas às necessidades humanas básicas, como saúde, educação, renda, lazer, etc.

\section{Escala humana como base norteadora do desenvolvimento local}

Alguns estudos nacionais e internacionais já apontam para a teoria da escala humana como sendo o aspecto primordial para o desenvolvimento local. Destacam-se aqui as contribuições, no âmbito nacional, as obras de Santos (2000) "Por uma outra Globalização. Do pensamento único à consciência universal"; Coriolano (2003) "Os limites do desenvolvimento e do Turismo"; Dowbor (2008) com "Democracia econômica: alternativas de gestão social". Já no cenário internacional tem-se a obra do chileno Max-Neef (1994) "Desarrollo a escala humana - conceptos, aplicaciones y algunas reflexiones"; de Hevia (2003) "Desarrollo Humano y Ética para la Sustentabilidad", etc.

O desenvolvimento na escala humana rompe com os paradigmas da economia ortodoxa quando propõe um desenvolvimento voltado para a qualidade de vida das pessoas, ou seja, quando todos os indivíduos satisfazem suas necessidades básicas. Este conceito foi desenvolvido pelo Centro de Alternativas de Desarrollo - Cepaur - no Chile e pela Fundação Dag Hammarskjold, na Suécia, em 1986, em especial por Manfred Max-Neef e apoio de Antonio Elizalde Hevia e Martín Hoppenhayn (GONZÁLEZ, 2009).

Para Max-Neef (1994), as necessidades humanas são as mesmas em qualquer tempo e cultura, o que se modifica são os modos empregados na sua forma de satisfação e os recursos utilizados para alcançar suas necessidades. Este autor propôs um sistema de matriz das necessidades fundamentais aplicadas aos países europeus e latino-americanos. A matriz, que traz a relação das necessidades humanas em duas ca- 
tegorias: axiológicas (subsistência, proteção, afeto, entendimento, participação, ócio, criação, identidade e liberdade) e existenciais (ser, estar, fazer e ter), foi de suma importância, pois quando relacionados a partir das linhas e colunas percebe-se os "satisfatores" que são os meios de atender às necessidades. Vale frisar a importância desses meios ("satisfatores") para o desenvolvimento local, pois quando a necessidade humana não é satisfeita de maneira adequada pode produzir patologias coletivas (doenças), como o desemprego, a marginalidade, entre outras (MAX-NEEF, 1994).

Os "satisfatores", segundo Alkire (2002), são denominados como "ingredientes para a qualidade de vida". Este autor traz as contribuições dos seguintes autores: Martha Nussbaum, que resgata as dimensões vida, saúde, interação, emoções, raciocínio prático, etc.; Deepa Narayan et al., com as dimensões bem-estar material, bem-estar do corpo, bem-estar social, segurança, liberdade de escolha e ação; bem-estar psicológico; Doyal e Gough, que abordam as dimensões comida, água, casa protegida, trabalho, ambiente físico, cuidados de saúde, segurança na infância, relações primárias significantes, segurança física, segurança econômica, controle de nascimento seguro, educação básica, etc. (ALKIRE, 2002).

Vale frisar que estes "satisfatores" denominados por Max-Neef (1994) também são encontrados com outra nomenclatura na obra dos economistas Musgrave e Musgrave (1980), os quais analisam a teoria e a prática das finanças públicas e a relação das três funções econômicas (alocativa, distributiva e estabilizadora) que o Estado apresenta. Para Musgrave e Musgrave (1980), os "satisfatores" na função alocativa são considerados bens públicos (rodovias, iluminação, segurança, saneamento, etc.) e semipúblicos (educação, saúde, desenvolvimento, etc.). Estes "satisfatores" destinam-se às necessidades básicas da população. Neste aspecto, o presente estudo identifica que os "satisfatores" de Max-Neef (1994) juntamente com as abordagens destes autores citados por Alkire (2002) e dos economistas Musgrave e Musgrave (1980) podem ser relevantes para a criação das dimensões e dos indicadores voltados para as políticas públicas do turismo sob o enfoque da escala humana.

\section{Contribuições da literatura para a construção da estrutura analítica}

Com base na revisão abordada, foi desenvolvida a estrutura teórico-conceitual a que se propôs o presente estudo, envolvendo os principais aspectos discutidos no ambiente acadêmico englobando o fenômeno do desenvolvimento local sob o enfoque da escala humana e o setor do turismo.

Para a construção da estrutura analítica foram utilizadas as ideias de Max-Neef (1994) sobre a Escala Humana e o uso dos "satisfatores", assim como dos autores Alkire (2002) com os "ingredientes para a qualidade de vida" e Musgrave e Musgrave (1980) com os bens públicos e semipúblicos.

As necessidades ("satisfatores") encontradas na literatura destes autores citados foram: emprego, renda, educação, saúde, saneamento e desenvolvimento. Já os indicadores que mais se identificavam com os "satisfatores" propostos foram: emprego formal nas Atividades Características do Turismo - ACTs; número de estabelecimentos turísticos representados por hotéis e similares, segundo classificação apresentada em IBGE (2003); renda média mensal do trabalhador formal; taxa de analfabetismo; número de matrículas iniciais; número de estabelecimentos de ensino; número de leitos hos- 
pitalares; cobertura de água nos domicílios; cobertura de esgoto nos domicílios; coleta de lixo nos domicílios; Índice de Qualidade de Vida - IQV; Índice de Desenvolvimento Humano Municipal - IDHM. A partir destes indicadores foi possível identificar as dimensões, a saber: Empregabilidade; Renda; Educação; Saúde; Saneamento; Qualidade de vida (Quadro 1).

Quadro 1 - Síntese das necessidades humanas e suas respectivas dimensões e indicadores

\begin{tabular}{|c|c|c|c|}
\hline AUTORES & NECESSIDADES & INDICADORES & DIMENSÕES \\
\hline $\begin{array}{l}\text { MAX-NEEF (1994) } \\
\text { (SATISFATORES) }\end{array}$ & $\begin{array}{l}\text { 1) Emprego } \\
\text { 2) Renda } \\
\text { 3) Educação } \\
\text { 4) Saúde } \\
\text { 5) Saneamento } \\
\text { 6) Desenvolvimento }\end{array}$ & \multirow{3}{*}{$\begin{array}{l}\text { 1) Emprego formal nas ACTs. } \\
\text { 1) Número de estabelecimentos } \\
\text { turísticos. } \\
\text { 2) Renda média mensal do } \\
\text { trabalhador formal. } \\
\text { 3) Taxa de analfabetismo. } \\
\text { 3) Número de matrículas iniciais. } \\
\text { 3) Número de estabelecimentos } \\
\text { de ensino. } \\
\text { 4) Número de leitos hospitalares. } \\
\text { 5) Cobertura de água nos } \\
\text { domicílios. } \\
\text { 5) Cobertura de esgoto nos } \\
\text { domicílios. } \\
\text { 5) Coleta de lixo nos domicílios. } \\
\text { 6) Índice de Qualidade de Vida - } \\
\text { IQV. } \\
\text { 6) Índice de Desenvolvimento } \\
\text { Humano Municipal - IDHM. }\end{array}$} & \multirow{3}{*}{$\begin{array}{l}\text { 1) Empregabilidade } \\
\text { 2) Renda } \\
\text { 3) Educação } \\
\text { 4) Saúde } \\
\text { 5) Saneamento } \\
\text { 6) Qualidade de vida }\end{array}$} \\
\hline $\begin{array}{l}\text { ALKIRE (2002): } \\
\text { Martha Nussbaum } \\
\text { Deepa Narayan et al. } \\
\text { Doyal e Gough } \\
\text { (INGREDIENTES PARA } \\
\text { A QUALIDADE DE } \\
\text { VIDA) }\end{array}$ & $\begin{array}{l}\text { 1) Emprego } \\
\text { 2) Renda } \\
\text { 3) Educação } \\
\text { 4) Saúde } \\
\text { 5) Saneamento } \\
\text { 6) Desenvolvimento }\end{array}$ & & \\
\hline $\begin{array}{l}\text { MUSGRAVE \& } \\
\text { MUSGRAVE (1980) } \\
\text { (BENS PÚBLICOS E } \\
\text { SEMIPÚBLICOS) }\end{array}$ & $\begin{array}{l}\text { 3) Educação } \\
\text { 4) Saúde } \\
\text { 5) Saneamento } \\
\text { 6) Desenvolvimento }\end{array}$ & & \\
\hline
\end{tabular}

Fonte: MUSGRAVE; MUSGRAVE (1980); MAX-NEEF (1994); ALKIRE (2002), adaptado por Aychá Freitas Santos (2016).

Com base nessa estrutura pretende-se viabilizar a avaliação dos resultados de um programa específico associado a uma Política Nacional do Turismo, o Prodetur, sob o enfoque específico da Escala Humana, trazendo uma nova perspectiva analítica a este setor da economia nacional.

\section{PROCEDIMENTOS METODOLÓGICOS}

O problema indutor deste estudo volta-se ao entendimento de como o Prodetur, como um dos mais bravos operacionais da Política Nacional de Turismo, pode contribuir para a promoção do desenvolvimento local, segundo a ótica da Escala Humana.

Dada a complexidade do propósito deste estudo, optou-se por mesclar diferentes estratégias de pesquisa. No primeiro momento utilizou-se a pesquisa histórica para compreender melhor as políticas públicas inseridas tanto no Brasil quanto no Estado da Bahia. No segundo momento foi priorizada a busca da identificação dos principais aspectos que Max-Neef e outros autores, voltados para esta abordagem da "Escala Humana", consideram importantes para a qualidade de vida das pessoas. Já no terceiro momento buscou-se a identificação dos dados secundários, associados direta ou indiretamente à atividade do turismo, obtidos nos bancos de dados do governo federal e do Estado da Bahia: Programa de Desenvolvimento do Turismo - Prodetur, Instituto Brasileiro de Geografia e Estatística - IBGE, Ministério do Trabalho: Rais/Caged, Ministério da Saúde: Datasus; Superintendência de Estudos Econômicos e Sociais da Bahia - SEI. 
A organização dos dados coletados deu-se por intermédio de cada dimensão (empregabilidade, renda, educação, saúde, saneamento, qualidade de vida) e dos respectivos indicadores (emprego formal nas ACTs; número de estabelecimentos turísticos; renda média mensal do trabalhador formal; taxa de analfabetismo; número de matrículas iniciais; número de estabelecimentos de ensino; número de leitos hospitalares; cobertura de água nos domicílios; cobertura de esgoto nos domicílios; coleta de lixo nos domicílios; IQV; IDHM.), os quais foram criados a partir da literatura dos autores Musgrave e Musgrave (1980), Max-Neef (1994) e Alkire (2002), demonstrados na seção anterior e no Quadro 1. Para discussão e análise destes dados foi realizado um ranking com os 154 municípios baianos pertencentes exclusivamente as 13 Zonas Turísticas, nos anos 2000 e 2010.

\section{ESTRUTURA TEÓRICO-CONCEITUAL PARA ANÁLISE DO DESENVOLVIMENTO GERADO PELO SETOR DE TURISMO, SOB O ENFOQUE DA ESCALA HUMANA}

A obra de Max-Neef (1994) não aponta quais os indicadores são fundamentais para sanar as necessidades humanas básicas, mas a partir da pesquisa identificou-se por meio de uma revisão de literatura dos autores Musgrave e Musgrave (1980), Max-Neef (1994) e Alkire (2002), alguns satisfatores/indicadores que se encontram presentes na formulação de políticas públicas e que visam à qualidade de vida do indivíduo: renda, emprego, saúde, educação, saneamento e desenvolvimento. Diante das abordagens teóricas e conceituais consideradas neste estudo, foram identificados os seguintes indicadores, agrupados em suas respectivas dimensões de análise:

i) Dimensão Empregabilidade: está vinculada às medidas específicas dos aspectos relacionados às necessidades humanas, associados à geração de riqueza. Os indicadores utilizados foram "emprego formal por Atividades Características do Turismo - ACTs" e "número de estabelecimentos turísticos". Neste estudo para a composição dos indicadores relativos a dimensão "Empregabilidade" foi embasada nos dados disponibilizados pelo Cnae 95 (referente ao ano 2000) e Cnae 2.0 para o ano de 2010. Com estes dois indicadores é possível fazer uma análise da geração de empregos no setor e sua relação com o número de unidades de negócio.

ii) Dimensão Renda: considerada um elemento essencial de subsistência e vista como uma das maneiras de sanar as necessidades humanas básicas. $\mathrm{O}$ indicador associado a esta dimensão é "renda média mensal do trabalhador formal no setor do turismo", sendo o rendimento médio dos trabalhadores, de um determinado grupo, que apresentam as mesmas atividades turísticas para cada período de análise. Seguem a classificação das ACTs da Cnae 95 e Cnae 2.0.

iii) Dimensão Educação: os indicadores desta dimensão fazem relação não exclusiva com o setor do turismo, mas são relevantes no contexto das políticas públicas, uma vez que se relacionam a várias dimensões essenciais para o atendimento das necessidades básicas e o bem-estar social, indo de encontro às proposições de Max-Neef (1994). Nesse contexto, a presente dimensão engloba três indicadores: o indicador "taxa de analfabetismo", que corresponde ao percentual de pessoas com 15 anos ou mais de idade que não sabem ler e escrever, na população total residente da mesma faixa etária, em determinado espaço geográfico, no ano considerado. Os indica- 
dores "número de matrículas iniciais" e "número de estabelecimentos de ensino" abrangem as variáveis relacionadas à Educação Infantil, Ensino Fundamental, Ensino Médio e Educação de Jovens e Adultos, nas dependências administrativas estadual, federal, municipal e privada.

iv) Dimensão Saúde: é uma das necessidades fundamentais e um direito de todos os cidadãos, garantidos na Constituição Federal de 1988. O conceito de saúde acha-se aqui associado à inclusão dos fatores relativo a doenças associados às questões sociais. Nesse contexto, entende-se que o indicador "número de leitos hospitalares" supra o propósito analítico deste estudo, uma vez que mede a relação entre a oferta de leitos hospitalares e a população residente na mesma área geográfica. Este indicador traz relação direta com a abordagem humanística do desenvolvimento, que por sua vez está relacionado às políticas setoriais de desenvolvimento econômico, que também se relacionam à construção da base dos fatores essenciais associados à qualidade de vida. Além disso, este indicador permite contextualizar o status da infraestrutura de saúde nas regiões turísticas, sobretudo permitindo identificar a capacidade de atendimento à demanda gerada pela atividade turística regional.

v) Dimensão Saneamento: é importante para as políticas públicas do turismo, como forma de propiciar à região melhorias na infraestrutura urbana e consequentemente maior atração de turistas. Este é um dos fatores considerados relevantes no Programa de Desenvolvimento do Turismo - Prodetur - o qual deixa claro a importância de investimentos voltados para a área do saneamento, Nesta perspectiva foram considerados os indicadores "cobertura de água nos domicílios (água canalizada rede geral)", "cobertura de esgoto nos domicílios (rede geral de esgoto)" e "coleta de lixo nos domicílios (coletado por serviço de limpeza)".

vi) Dimensão Qualidade de Vida: para Max-Neef (1994), as necessidades humanas serão sanadas quando houver de fato uma qualidade de vida digna e bem-estar social e nesse sentido Villota (1981) apresenta o "Índice de Qualidade de Vida - IQV" - composto por três variáveis: esperança de vida ao nascer, taxa de mortalidade infantil e taxa de alfabetização da população, considerados elementos essenciais para a qualidade de vida de um ser humano. O cálculo do IQV é realizado a partir da média aritmética destas três variáveis. Esta dimensão é construída com base no IQV, que é um índice que, associado ao Índice de Desenvolvimento Humano nos Municípios - IDH - M-, trata das características peculiares do desenvolvimento humano no município em um determinado período, o qual consiste na média geométrica dos índices das dimensões renda, educação e longevidade, com pesos iguais.

\section{ANÁLISE DAS POLÍTICAS PÚBLICAS E DESENVOLVIMENTO LOCAL SOB A ÓTICA DA ESCALA HUMANA NAS ZTS - BAHIA}

Nesta seção serão analisados os municípios e suas respectivas Zonas Turísticas a partir dos indicadores escolhidos e dimensões, os quais podem contribuir para o desenvolvimento local sob o enfoque da Escala Humana. A seguir são apresentados, para cada uma das dimensões analíticas propostas, os resultados, em função da estrutura proposta neste estudo. 


\section{Dimensão Empregabilidade}

No ano 2000 foram gerados nos 154 municípios das 13 Zonas Turísticas do Estado da Bahia um total de 44.067 empregos formais com ACTs. Já no ano 2010 este número de empregos formais passou para 83.698. Vale frisar, no entanto, que a análise do crescimento do nível de empregados no setor de turismo não pode ser unilateralmente associada a uma política setorial, "haja vista que o nível de emprego na atividade turística é condicionado, não apenas ao próprio nível de desenvolvimento da atividade, mas também a aspectos como a sazonalidade e, sobretudo, a questões de caráter macroeconômico" (MATIAS, 2008, p. 129-130). Em relação ao município que apresentou maior número de empregos formais com ACTs em 2000 e 2010 destaca-se Salvador, com respectivamente 28.157 e 38.170 empregos formais.

Quanto aos segmentos das ACTs o que mais cresceu em relação ao Estado da Bahia nos anos 2000 e 2010 foi o segmento de alimentação, com 48,61\% e 47,73\% respectivamente. Vale frisar que esse crescimento do segmento de alimentação limita a análise do turismo, pois este setor não é considerado exclusivamente da atividade turística, apesar de ser bastante relacionado.

Com relação ao número de estabelecimento turísticos, em 2000 foram criados 4.801 estabelecimentos turísticos e em 2010 este número alcançou a marca de 9.297 nas 13 Zonas Turísticas baianas. A sua distribuição está concentrada na Zona Turística Baía de Todos os Santos, com 55,78\% e 42,77\% dos estabelecimentos, no período 2000 e 2010, respectivamente. Resultado semelhante foi também observado para o indicador "número de emprego formal nas ACTs", enfatizando assim que as políticas públicas do turismo, principalmente Prodetur/NE, continuam beneficiando a Zona Baía de Todos os Santos e seus respectivos municípios. Quando analisados os municípios isoladamente foi possível notar que tanto no ano 2000 quanto no ano 2010 o município de Salvador ocupou a primeira posição no número de estabelecimentos turísticos.

Nota-se, no entanto, que tanto o indicador de "número de empregos formais nas ACTs" quanto o indicador "número de estabelecimentos turísticos" apresentam uma realidade diferente dos objetivos do Programa de Desenvolvimento do Turismo na Bahia. Os indicadores foram essenciais para observar que a política pública adotada pelo Prodetur/BA ainda não se tornou efetiva, uma vez que não houve de fato uma meIhoria significativa dos municípios de pequeno porte, contemplando com investimentos aqueles que já possuem outras atividades econômicas de maior relevância para o crescimento do Estado, principalmente os que fazem parte da Região Metropolitana de Salvador, além dos municípios que estão próximos ao litoral.

De maneira global, sob o foco analítico das políticas públicas, os resultados dessa dimensão analítica sugerem que as políticas públicas voltadas para o turismo ainda se apresentam presas à hierarquia do tipo top-down, em que a participação dos alvos dessas políticas nem sempre assumem papel protagonista no processo. Isso se dá, fundamentalmente, em razão de que o turismo ainda não se consolidou no Brasil como uma atividade dotada de políticas de Estado, que transpassam governos e suas políticas de gestão. 


\section{Dimensão Renda}

No que diz respeito aos rendimentos mensais oriundos dos empregos formais das atividades características do turismo, verificou-se que a renda média mensal do trabaIhador formal nos municípios baianos das 13 Zonas Turísticas foi de $\mathrm{R} \$ 176,00$ no ano 2000 e no ano 2010 a renda média mensal nos municípios das Zonas Turísticas foi de $\mathrm{R} \$ 510,00$. Percebe-se uma tímida valorização da renda nos municípios da Bahia que possuem o turismo como atividade crucial para a economia, pois se comparado com o salário mínimo no período de $2000^{3}$ e $2010^{4}$, $\mathrm{R} \$ 151,00$ e $\mathrm{R} \$ 510,00$ respectivamente, observa-se que o setor do turismo ficou acima desse parâmetro no ano 2000 e no ano 2010 obteve o mesmo valor.

Os municípios considerados de pequeno e médio porte foram os mais beneficiados com as atividades características do turismo. Em 2000 o município com maior rendimento médio mensal foi Castro Alves (R\$ 674,00), inserido na Zona Turística Caminhos do Jiquiriçá, e no ano 2010 o município que ocupou o primeiro lugar foi Una (R\$ $1.307,00)$, inserido na Zona Turística Costa do Cacau.

\section{Dimensão Educação}

A análise mostra nos 154 municípios das 13 Zonas Turísticas da Bahia, no ano 2000, uma variação entre 5,7\% e 46,4\% analfabetos. Esta faixa foi reduzida no ano 2010 para valores entre $3,9 \%$ e $39,1 \%$ de analfabetos. O município com maior taxa de analfabetos em 2000 foi Maraú, com 46,4\%, e o com menor taxa de analfabetos no mesmo ano foi Salvador, com 5,7\%. Em 2010 o município com maior taxa foi Itapicuru, com $39,1 \%$, e Salvador manteve-se como o de menor taxa de analfabetismo, com 3,9\% de analfabetos. Nota-se, portanto, uma redução de analfabetos nos 154 municípios, possivelmente fruto de políticas públicas específicas desenvolvidas pelos governos federal e estadual no período de estudo, nos anos 2000 e 2010, políticas específicas como o Programa Estadual Topa - Todos Pela Educação, entre outras.

O Prodetur/BA é uma das políticas públicas que tem como diretriz alavancar a educação nos municípios baianos que são considerados atrativos turísticos. Não se pode deixar de considerar, entretanto, que neste mesmo período (2000/2010) houve melhora na geração de renda dos trabalhadores associados ao turismo, que por sua vez sugere maior disponibilidade para conseguir acesso e manutenção às estruturas de ensino, associadas a essas políticas.

A Zona Turística com maior número de matrículas iniciais no período 2000/2010 foi a Baía de Todos os Santos, com 32,82\% e 28,81\% respectivamente. Já a Zona com menor número de matrículas iniciais no período 2000/2010 e que obteve a mesma porcentagem foi Lagos e Cânions de São Francisco, com 1,88\%. Esses dados evidenciam uma tendência já observada nas outras dimensões, de maior acesso a políticas públicas a localidades mais populosas. Quando analisados os municípios baianos separadamente percebe-se que Salvador lidera a lista no ano 2000 e no ano 2010, com 761.965 e 548.485 matrículas respectivamente.

${ }^{3}$ R\$ 210,00 (Lei 9.971/2000).

${ }^{4} \mathrm{R} \$ 510,00$ (Lei 12.225/2010) 
O número de matrículas iniciais segue o mesmo comportamento observado para os indicadores referentes às matrículas. O município com maior número de estabelecimentos de ensino nos anos 2000 e 2010 foi Salvador, com respectivamente 2.006 e 2.071. Já o município que teve o menor número de estabelecimentos de ensino nas 13 Zonas Turísticas em 2000 foi Rodelas, com apenas 16 estabelecimentos, e em 2010 o município com menor número de estabelecimentos foi Dom Macedo Costa, com apenas 15 estabelecimentos, o mesmo município com menor número de matrículas iniciais no período de 2000/2010.

Os indicadores aqui analisados foram capazes de avaliar que há ainda uma carência quanto ao número de pessoas analfabetas, principalmente no interior da Bahia, o que pode dificultar na geração de empregos relacionados às atividades características do turismo.

\section{Dimensão Saúde}

Quando avaliado o número total de leitos hospitalares nos 154 municípios baianos, no período 2000/2010, verificou-se um aumento absoluto de 20.870 para 21.100 leitos hospitalares, respectivamente. Verifica-se que a Zona Turística com maior quantidade de leitos hospitalares, nos anos 2000 e 2010, é a Zona Baía de Todos os Santos, com $40,41 \%$ e $40,84 \%$ respectivamente. Quando analisados os municípios baianos individualmente, notou-se que o município com maior número de leitos hospitalares, nos anos 2000 e 2010, foi Salvador, com 7.451 e 7.799 leitos respectivamente. Quando verificados os municípios com menor número de leitos hospitalares no período 2000/2010, em 2000 o município de Saubara, com 8 leitos hospitalares, foi o que apresentou o menor número de leitos e em 2010 este status ficou para o município de Candeal, com 3 leitos hospitalares.

Esses resultados relacionados à disponibilização de leitos hospitalares sugerem uma fragilidade dos equipamentos de saúde tanto para a população residente quanto para os visitantes/turistas, para quem esses equipamentos devem ser considerados. Nesse contexto vale frisar que as ideias de Max-Neef (1994) sobre o Desenvolvimento na Escala Humana, consideram além da infraestrutura básica eficaz (escolas, postos de saúde, saneamento, etc.), uma qualidade melhor no atendimento às necessidades públicas, entre elas, neste caso: o acesso à saúde. A dimensão saúde também é essencial para o turismo, pois quando o município apresenta alto índice de doentes deixa de ser apreciado pelos turistas.

\section{Dimensão Saneamento}

Com relação à estrutura de saneamento básico, nas Zonas Turísticas estudadas existiam em 2000 1.526.847 domicílios com água canalizada, e em 2010 este número aumentou para 2.419 .368 , representando um crescimento na ordem de $58,46 \%$ no período. A Zona Turística com maior sistema de abastecimento de água por rede geral nos domicílios, no período 2000/2010, foi Baía de Todos os Santos, com 45,91\% (700.928 domicílios) e 40,11\% (970.325 domicílios) respectivamente. Este grande resultado encontrado na Zona Baía de Todos os Santos só foi possível devido aos investimentos realizados para o setor de saneamento (BAHIA, 2003). 
Quando analisados os 154 municípios separadamente, pôde-se verificar que o município de Salvador cresceu no número de domicílios com cobertura de água canalizada por rede geral. Segundo Bahia (2003), o município de Salvador possuía em 2000 um total de 651.293 domicílios, dos quais 628.854 eram contemplados com cobertura de água canalizada por rede geral, o que corresponde a mais de $95 \%$ da população com atendimento ao sistema da rede geral de abastecimento. 0 município que possui menor cobertura de água canalizada por rede geral no período 2000/2010 foi Dom Macedo Costa, com respectivamente 308 e 1.063 domicílios com água canalizada. Esses dados sugerem o fortalecimento da tendência observada neste estudo, da concentração de benefícios provenientes de políticas públicas nas áreas com maior acumulação populacional.

Mesmo comportamento foi observado aos dados relativos à coleta de esgoto, que demonstram haver em 2000847.434 domicílios com cobertura de esgoto rede geral, nos 154 municípios pertencentes as 13 Zonas Turísticas do Estado da Bahia. Já em 2010 houve um aumento percentualmente expressivo de domicílios com cobertura de esgoto rede geral, passando a ter 2.755.843 de domicílios nas 13 Zonas Turísticas da Bahia, representando um crescimento de $225,2 \%$. Trata-se de um crescimento bem superior ao observado no mesmo período para o abastecimento de água nos domicílios. A Zona Turística com maior cobertura de esgotamento sanitário na modalidade rede geral, no período 2000/2010, foi a Zona Baía de Todos os Santos, com 61,09\% e 30,33\% domicílios respectivamente.

Atenta-se para o fato de que muitos municípios, em 2000, com situações precárias no sistema de esgotamento sanitário, foram da Zona Turística Chapada Diamantina, Baía de Todos os Santos, Caminhos do Jiquiriçá, Caminhos do Oeste, Caminhos do Sertão e Costa dos Coqueiros. Em 2010 os municípios com situações precárias no sistema de esgotamento sanitário foram das Zonas: Caminhos do Jiquiriçá, Caminhos do Sertão, Chapada Diamantina e Costa dos Coqueiros. Nota-se a partir do indicador "cobertura de esgoto rede geral" que os municípios baianos das Zonas Turísticas possuíam no período 2000/2010 uma deficiência ainda grande no sistema de esgotamento sanitário em relação ao sistema de abastecimento de água, principalmente aqueles considerados de pequeno porte.

A Zona Turística Baía de Todos os Santos é a que possui maior cobertura de coleta de lixo por serviço de limpeza no período $2000 / 2010$, com respectivamente $42,28 \%$ e $35,56 \%$ domicílios, respectivamente. A Zona Turística Baía de Todos os Santos foi a mais contemplada com investimentos na área de saneamento, isto porque os governos federal e estadual instituíram o Programa Baía Azul na Zona Turística (BAHIA, 2011). Já a Zona Turística com menor número de domicílios que apresentaram a coleta de lixo por serviço de limpeza em 2000 foi a Costa do Dendê, com 1,46\%, e em 2010 a Zona Turística que ocupou a última posição foi Lagos e Cânions do São Francisco, com 1,93\%. Em relação ao município com maior cobertura de coleta de lixo por serviço de limpeza, no período 2000/2010 foi Salvador, com respectivamente 436.868 e 525.923 domicílios.

Também é relevante apontar que a análise destes indicadores apresentados na dimensão saneamento torna-se importante para o desenvolvimento local sob o enfoque da Escala Humana. Quando a infraestrutura pública é adequada, o setor turístico pode alavancar na localidade, possibilitando o desenvolvimento. 


\section{Dimensão Qualidade de Vida}

Dos 154 municípios baianos, indutores do turismo, pertencentes as 13 Zonas Turísticas, possuíam uma variação, em 2000, de 16,25 a 31,78 de IQV e em 2010 esta variação foi de 21,66 a 33,19 de IQV. O município de Salvador foi o que teve maior IQV no período 2000/2010, com respectivamente 31,78 e 33,19. Quando observados os municípios com menores índices de qualidade de vida, nota-se que Itapicuru é o que possui menor IQV, tanto no ano 2000 quanto no ano 2010, com respectivamente, 16,25 e 21,66. As Zonas Turísticas dos municípios com maiores IQV foram: Baía de Todos os Santos, Caminhos do Oeste, Caminhos do Sertão, Caminhos do Sudoeste, Chapada Diamantina, Costa do Cacau e Costa dos Coqueiros, ou seja, das 13 Zonas Turísticas, 7 apresentam municípios com maior IQV no período 2000/2010.

Com relação ao IDH-M no ano de 2000 , foi observada uma variação nos municípios indutores do turismo na Bahia de $0,283 \%$ a $0,654 \%$, correspondente às faixas de classificação Pnud, entre "muito baixo" a "médio". Já no ano 2010 houve uma melhora no espectro desta variação. Nesse ano a variação foi de $0,486 \%$ a $0,759 \%$, classificando-se como "muito baixo" a "alto". Quando verificados os municípios com maiores Índices de Desenvolvimento Humano Municipal, notou-se que Salvador no período 2000/2010 obteve o maior IDH-M entre os municípios pertencentes as 13 Zonas Turísticas da Bahia, com respectivamente $0,654 \%$ e $0,759 \%$. Atenta-se para o fato de que o IDH-M do município de Salvador, no período 2000/2010, estava acima do IDH do Estado da Bahia $(0,512 \%$ e $0,660 \%)$ e do Brasil $(0,612 \%$ e $0,727 \%)$.

Os indicadores utilizados na dimensão qualidade de vida foram essenciais para reforçar a linha de entendimento de que o desenvolvimento, sobretudo quando associado à dimensão humana de sua concepção, só pode ser considerado quando as necessidades básicas sociais são atendidas. Os resultados aqui obtidos revelaram ao mesmo tempo um tímido acréscimo de renda no período analisado, ao mesmo tempo que neste mesmo período carências estruturais, sobretudo na área de saneamento, também compuseram este cenário.

\section{CONSIDERAÇÕES FINAIS}

O objetivo deste artigo foi propor uma estrutura analítica para avaliação das políticas públicas do turismo, na condição de agente de promoção do desenvolvimento local, sob a ótica da Escala Humana. Vale frisar que as dimensões empregabilidade e renda estão diretamente relacionadas com as políticas públicas do turismo, e que a presença das dimensões da educação, saúde, saneamento e qualidade de vida tornam-se essenciais para a avaliação das políticas públicas sob o enfoque do desenvolvimento local pela lente da Escala Humana e também mostram-se relacionadas às atividades turísticas, seja como reflexo do aumento da renda proporcionada por esta atividade, ou pelo suporte à estrutura capaz de absorver os turistas ou de garantir a força de trabalho local.

Diante das políticas públicas do turismo apresentadas neste artigo, evidenciou-se que o Programa de Desenvolvimento do Turismo - Prodetur - mostrou afinidade com o princípio do desenvolvimento local a partir da ótica humanística, apresentada por Max-Neef (1994), ao mesmo tempo que mantém um intenso caráter de exigência quanto à proposição e estratégias operacionais de uma política específica. A análise dos resulta- 
dos deste estudo revela que o Prodetur/BA, mesmo valendo-se dessa afinidade, apresentou um caráter relacionado ao desenvolvimento exógeno, os recursos/investimentos viabilizados para a melhoria da infraestrutura básica dos municípios turísticos baianos concentrou-se nas áreas já então desenvolvidas e com um crescimento significativo nos setores econômicos, não somente no setor turístico.

Diante disso, constata-se que as políticas públicas do turismo, tanto federal quanto estadual, trouxeram seus maiores impactos positivos aos lugares que já possuem atrativos turísticos historicamente consolidados, enquanto outros municípios, que carecem de maiores atrativos turísticos e infraestrutura básica, não tiveram os mesmos investimentos e consequentemente a mesma proporção de resultados.

Vale frisar, no entanto, que as políticas públicas podem contribuir para a promoção do desenvolvimento local, sob o enfoque da Escala Humana, quando atenderem às necessidades básicas do cidadão, ou seja, quando estes forem assistidos efetivamente nos setores da saúde, do saneamento básico, da educação, etc. Dessa forma, avaliar as políticas públicas a partir do embasamento teórico de Max-Neef (1994) sobre a Escala Humana, assim como da matriz das necessidades básicas e seus "satisfatores", torna-se uma das alternativas para a análise do desenvolvimento local.

\section{REFERÊNCIAS}

ALKIRE, S. Dimensions of Human Development. World Development, 30 (2), p. 181-205, 2002.

ALVES, J. A. B. O turismo como fator de contribuição para o desenvolvimento local: uma análise do planejamento municipal de Piraquara - Paraná. 2008. Monografia (Especialização em Planejamento e Gestão do Turismo) - Universidade Federal do Paraná, Departamento de Turismo, Setor de Ciências Humanas, Letras e Artes, Curitiba, 2008.

BAHIA. Secretaria de Turismo do Estado da Bahia. Plano de Desenvolvimento Integrado do Turismo Sustentável - PDITS - Salvador e entorno. Bahia, Brasil, 2003.

BAHIA. Secretaria de Turismo do Estado da Bahia. Plano de Desenvolvimento Integrado do Turismo Sustentável - PDITS - Baía de Todos os Santos. Bahia, Brasil, 2011.

BRASIL. Plano Nacional do Turismo: diretrizes, metas e programas. 2003-2007. Brasília: Ministério do Turismo, 2003.

BRASIL. Ministério do Turismo. 2015. Disponível em: www.turismo.gov.br. Acesso em: 17 fev. 2016.

CORIOLANO, L. N. Os limites do desenvolvimento e do turismo. In: Pasos. Revista de Turismo y Patrimonio Cultural, v. 1, n. 2, p. 161-171, 2003. ISSN 1695-7121.

CORIOLANO, L. N. A contribuição do turismo ao desenvolvimento local. In: PORTUGUEZ, Anderson Pereira; SEABRA, Giovanni; QUEIROZ, Odaléia Telles M. M. (org.). Turismo, espaço e estratégias de desenvolvimento local. João Pessoa: Editora Universitária da UFPB, 2012. 396 p. Disponível em: http://www.geociencias.ufpb.br/ paulorosa/Documentos/Divulgacao/livros/livroGEPTEEDL.pdf. Acesso em: 8 nov. 2015. CRUZ, R. de C. A. da. Política de turismo e território. São Paulo: Contexto, 2000.

CRUZ, R. de C. A. da. Introdução à geografia do turismo. São Paulo: Roca, 2001.

CRUZ, R. de C. A. da. Planejamento governamental do turismo: convergências e contradições na produção do espaço. In: LEMOS, Amalia Inés Geraiges de; ARROYO, Mónica; SILVEIRA, María Laura. América Latina: cidade, campo e turismo. San Pablo: Consejo Latinoamericano de Ciencias Sociales - Clacso, 2006.

DOWBOR, L. Democracia econômica: alternativas de gestão social. Petrópolis, RJ: Vozes, 2008. 214 p.

FERREIRA, L. da S.; DANTAS, E. W. C. Decurso histórico do turismo no Estado da Bahia: Antônio Carlos Magalhães (ACM) e a cultura local como fatores intervenientes para o desenvolvimento da atividade. In: GeoTextos, v. 9, n. 1, p. 113-127, jul. 2013.

FURTADO, C. Introdução ao desenvolvimento - enfoque histórico-estrutural. 3. ed. Rio de Janeiro: Paz e Terra, 2000.

GONZÁLEZ, G. B. Desarrollo a escala humana. 2009. Disponível em: http://web.archive.org/ web/20090306050424/http://tsocial.ulagos.cl/apuntes/desarrolloescalahumana.pdf. Acesso em: 2 mar. 2016. 
HEVIA, A. E. Desarrollo Humano y Ética para la Sustentabilidad. Programa de las Naciones Unidas para el Medio Ambiente - PNUMA - Oficina Regional para América Latina y el Caribe. 2003. Disponível em: http://www.ambiente.gov.ar/infotecaea/descargas/elizalde01.pdf. Acesso em: 2 mar. 2016.

IBGE. Instituto Brasileiro de Geografia e Estatística. Economia do Turismo. Uma Perspectiva Macroeconômica, v. 2009, 2003.

KRIPPENDORF, J. Sociologia do turismo: por uma nova compreensão do lazer e das viagens. Tradução Contexto Traduções. 3. ed. São Paulo: Aleph, 2003.

LUCHIARI, M. T. D. P. Urbanização turística - um novo nexo entre o lugar e o mundo. In: LIMA, Luiz Cruz (org.). Da cidade ao campo: a diversidade do saber-fazer turístico. Fortaleza: Ed. Uece, 1998. p. 15-29.

MATIAS, K. C. de O. Políticas públicas para geração de empregos: considerações sobre o Proger Turismo. 2008. Dissertação (Mestrado) - UFPB, João Pessoa, 2008.

MAX-NEEF, M. Desarrollo a escala humana - conceptos, aplicaciones y algunas reflexiones. Barcelona: Icaria Editorial. 1994. 148p. Disponível em: http://www.max-neef.cl/descargas/Max_Neef-Desarrollo_a_ escala_humana.pdf. Acesso em: 8 nov. 2015.

MCINTOSH, R. W.; GOELDNER, C. R.; RITCHIE, J. Turismo: planeación, administración y perspectivas. México: Limusa, 2003.

MUSGRAVE, R. A.; MUSGRAVE, P. B. Finanças públicas: teoria e prática. São Paulo: Editora da Universidade de São Paulo, 1980. 673 p.

QUEIROZ, R. B. Formação e gestão de políticas públicas. Curitiba: InterSaberes; Livro Eletrônico, 2012.

RODRIGUES, A. B. Turismo e territorialidades plurais: lógicas excludentes ou solidariedade organizacional. In: LEMOS,A. I. G; ARROYO, M; SILVEIRA, M. L. (org.). América Latina: cidade, campo e turismo. São Paulo: CLACSO, 2006. p. 297-315.

RUA, M. G. Análise de políticas públicas: conceitos básicos. In: RUA, M. G.; CARVALHO, M. I. V. de (org.). O estudo da política: tópicos selecionados. Brasília: Paralelo 15, 1998.

SANTOS, M. Por uma outra globalização. Do pensamento único à consciência universal. Rio de Janeiro: Record, 2000.

SILVA, J. A. S. Turismo, crescimento e desenvolvimento: uma análise urbano-regional baseada em cluster. 2004. 480 f. Tese (Doutorado) - Escola de Comunicações e Artes; USP, 2004. V. 1 e v. 2.

SOUZA, C. Políticas públicas: uma revisão da literatura. Sociologias, Porto Alegre, a. 8, n. 16, p. 20-45, jul./ dez. 2006. Disponível em: http://www.scielo.br/pdf/soc/n16/a03n16. Acesso em: 4 dez. 2015.

SOUZA, R. O. de; MORAIS, J. M. L. Políticas públicas para o turismo: uma forma de incrementar o desenvolvimento econômico e social de uma região. Artigo científico. Caderno de Cultura e Ciência, Universidade Regional do Cariri - Urca, a. VI, v. 10, n. 2, dez. 2011 Disponível em: http://periodicos.urca.br/ojs/ index.php/cadernos/article/viewFile/411/pdf_1. Acesso em: 25 out. 2015.

URRY, J. The Tourism gaze. London: Sage, 2000.

VILLOTA, F. V. Concepto de desarrollo e indicadores de la calidad de la vida. In: Revista de Economía Política, n. 87, enero/abr. 1981.

ZAPATA, T. et al. Gestão participativa para o desenvolvimento local. Recife: Instituto de Assessoria para o Desenvolvimento Humano, 2004. 